Article

\title{
Study on Spontaneous Combustion Tendency of Coals with Different Metamorphic Grade at Low Moisture Content Based on TPO-DSC
}

\author{
Jiuyuan Fan ${ }^{1}$, Gang Wang ${ }^{1,2, *}$ and Jiuling Zhang ${ }^{3}$ \\ 1 College of Mining and Safety Engineering, Shandong University of Science and Technology, Qingdao 266590, \\ China; sdfanjiuyuan@163.com \\ 2 Mine Disaster Prevention and Control-Ministry of State Key Laboratory Breeding Base, \\ Shandong University of Science and Technology, Qingdao 266590, China \\ 3 Hebei Province Key Laboratory of Mine Development and Safety Technology, \\ North China University of Science and Technology, Tangshan 063210, China; ninety2000@163.com \\ * Correspondence: Gang.Wang@sdust.edu.cn; Tel.: +86-136-153-27361
}

Received: 14 September 2019; Accepted: 9 October 2019; Published: 15 October 2019

\begin{abstract}
In the environments of various open coal storage sites, mining-affected coalbeds, and goafs, etc., some coal bodies are often affected by external environmental factors. They are highly prone to spontaneous combustion in low moisture content $(\leq 8 \%)$. In order to examine the effect of low moisture content on the spontaneous combustion tendency of coals with different metamorphic grade, we conducted a temperature programmed oxidation (TPO) experiment and differential scanning calorimetry (DSC) experiment to study the spontaneous combustion characteristics of coals with different metamorphic grade at four different low moisture contents. The change laws of the characteristic parameters of four different metamorphic grade coals at four different low moisture contents were comparatively analyzed. The experimental results indicate that: (1) Compared other low moisture content, anthracite and fat coal at a low moisture content of $1.2 \%$ show a stronger tendency for spontaneous combustion, and long flame coal and lignite at a low moisture content of $3.4 \%$ and $5.6 \%$ are more prone to spontaneous combustion. (2) Four different metamorphic grade coals at a low moisture content of $7.8 \%$ are less prone to spontaneous combustion.
\end{abstract}

Keywords: low moisture content; metamorphic grade; temperature-programmed oxidation; differential scanning calorimetry; spontaneous combustion tendency

\section{Introduction}

Among many influencing factors of coal spontaneous combustion, it is widely recognized that moisture plays an important role [1-4]. From the increased probability of spontaneous combustion of coals after damp or flooding, some scholars realized that coal with different moisture contents has different thermal reaction characteristics [5,6]. In all kinds of open coal storage sites, coal washing plants, coal bunkers, power plants, etc., long-term open-air piles of static coal piles were piled up, and under the influence of sunlight or atmospheric wind, the moisture in the coal piles continuously evaporated [7]. Underground, moisture in orebody and surrounding rock seepage channels could evaporate due to roadway ventilation, airflow, or geological factors, especially under the influence of mining. After coal is immersed in moisture at the goaf, the moisture may gradually reduce due to the influence of long-term air leakage. In these environments, some coal will be in the low moisture content state [8] (low moisture content of coal, $\mathrm{Mt} \leq 8.0 \%$, according to China Coal Water Classification Industry Standards, MT/T 850-2000) due to the external environment, and once spontaneous combustion of coal 
occurs, it not only inevitably causes a waste of coal resources, environmental pollution, and economic losses, but also directly endangers the safety of field workers [9-14].

In recent years, researchers have extensively studied the effect of moisture on coal's spontaneous combustion characteristics [15]. From the view of moisture content's effect on coal's spontaneous combustion and its characteristic parameters, Arisoy and Beamish [16] found that high moisture content could slow down the process of coal's spontaneous combustion and make it unable to reach thermal runaway status. Xuyao et al. [17] found that high moisture content could postpone coal's self-heating process. Yu et al. [18] constructed a mathematical model for spontaneous combustion of moisture-bearing coals and concluded that moisture slows down the process of coal's spontaneous combustion. Kadioğlu and Varamaz [19] studied the spontaneous combustion characteristics of Turkish moisture-bearing coal samples at different dried conditions using the cross-point method and found that with increasing drying time and gradually decreasing moisture content, moisture-bearing coals were more reactive and prone to spontaneous combustion. Beamish and Hamilton [20] studied the effect of moisture on the R70 self-heating rate of coal by using adiabatic experiments and found that when coal's moisture content increased from dried state to $6 \%$, its R70 self-heating rate decreased by $50 \%$; when coal's moisture content was between $17 \%$ and $18.6 \%$, its R70 self-heating rate became zero; and when coal's moisture content reached $40-50 \%$ of its moisture-holding capacity, its self-heating rate began to increase significantly, thus, coal's actual moisture content above this critical level could greatly delay its spontaneous combustion cycle. Deng [21] found coals from Mengba Coal Mine were most sensitive to spontaneous combustion at a moisture content of $14.27 \%$. Song et al. [22] found that after water immersion, a large number of closed pores in long flame coal were unclogged, leading to enhanced ability to adsorb oxygen, reduced cross-point temperature, and increased concentration of index gases due to oxidation and high risk of spontaneous combustion. Wang et al. [23] showed that the threshold of coal's moisture content depended on its maximum oxygen consumption. When coal's moisture content exceeded the threshold, excessive water would form a multi-layer structure that hindered the diffusion of oxygen into pores and cracks in the coal, resulting in a slower chemical adsorption reaction between coal and oxygen. Zhang et al. [24] found that the swelling degree of the lignite matrix enhances at moisture content for the range of $10-30 \%$, which was favorable for the transportation or migration of oxygen in the coal. Li et al. [25] explored the effect of moisture content on lignite's characteristic temperature using a coal oxidation simulation device and concluded that at a critical moisture content of $15 \%$, heat released by lignite during the oxidation process reached its peak. Chen and Stott [26] found that at a moisture content of 7-17\%, oxygen adsorption by coals with low metamorphic grade from New Zealand reached the maximum. The moisture content of coal showed specific oxidation conditions in the range of $7-17 \%$. The reaction sites in coal's pores could be completely exposed to $\mathrm{O}_{2}$, and the residual moisture content enhanced the chemical reaction. Zhao et al. [27] oxidized Indonesian coal using a double-fixed quartz reactor and examined the effect of moisture content on the characteristics of coal under the low-temperature oxidation. It was found that the separation point temperature (SPT) as the starting point of self-heating of the coal was greatly affected by the coal's moisture content in the oxidation process. When the moisture content was in the range of $6-13 \%$, the SPT was the lowest. It was indicated that the coal had a rapid oxidation rate in this critical moisture content range. From the view of moisture content on the spontaneous combustion characteristics of coals with different metamorphic grade, Wang et al. [28] found that lignite was prone to spontaneous combustion at a moisture content of $35 \%$, above this critical value, its tendency to spontaneous combustion was not obvious, and when its moisture content was only $30 \%$, the spontaneous combustion was unlikely to occur. Xu et al. [29] tested the exothermic characteristics of lignite, gas coal, fat coal, and anthracite at different moisture content (10-25\%, 20-42\%) in their oxidation processes using TA-DSC (thermogravimetric analysis-differential scanning calorimetry). It showed that the influences of moisture content on coals with different metamorphic grade vary greatly. The critical moisture content for lignite and anthracite to have a higher tendency to spontaneous 
combustion are $25 \%$ and $20 \%$, respectively. In addition, for gas coal and fat coal, the lower their moisture content, the higher the risk of spontaneous combustion.

The above research on the effect of moisture content for the spontaneous combustion tendency of coals mainly focused on the spontaneous combustion characteristics of coals with medium or high moisture content (medium or high moisture content of coal, $\mathrm{Mt}=8.0-40 \%$, according to China Coal Water Classification Industry Standards, MT/T 850-2000) and low metamorphic grade, but rarely explored the spontaneous combustion tendency of coals with different metamorphic grade at low moisture content. Considering that spontaneous combustion may occur when coals with different metamorphic grade are in a state of low moisture content, for example, all kinds open coal storage sites, mining-affected coalbeds, goafs and other environments, in this paper we utilized the temperature programmed oxidation (TPO) experiment and differential scanning calorimetry (DSC) experiment to examine the change laws of spontaneous combustion tendency of anthracite, fat coal, long flame coal, and lignite at four different levels of low moisture content. The effect of moisture content on the spontaneous combustion tendency of coals is further expanded. Thus, this study is of practical significance for the prevention of spontaneous combustion of coals with low moisture content.

\section{Experiments and Methods}

\subsection{Coal Samples}

\subsubsection{Collection and Preparation}

The different metamorphic grade of the collected coal samples was ranked in a descending order as follows: anthracite from Changcun Coal Mine, Shanxi Province, China; fat coal from Tangshan Fangezhuang Coal Mine, Hebei Province, China; long flame coal from Inner Mongolia, Inner Mongolia Autonomous Region; China, lignite from Tangshan Cuijiazhai Coal Mine, Hebei Province, China; Figure 1 shows the locations where the coal samples were collected.

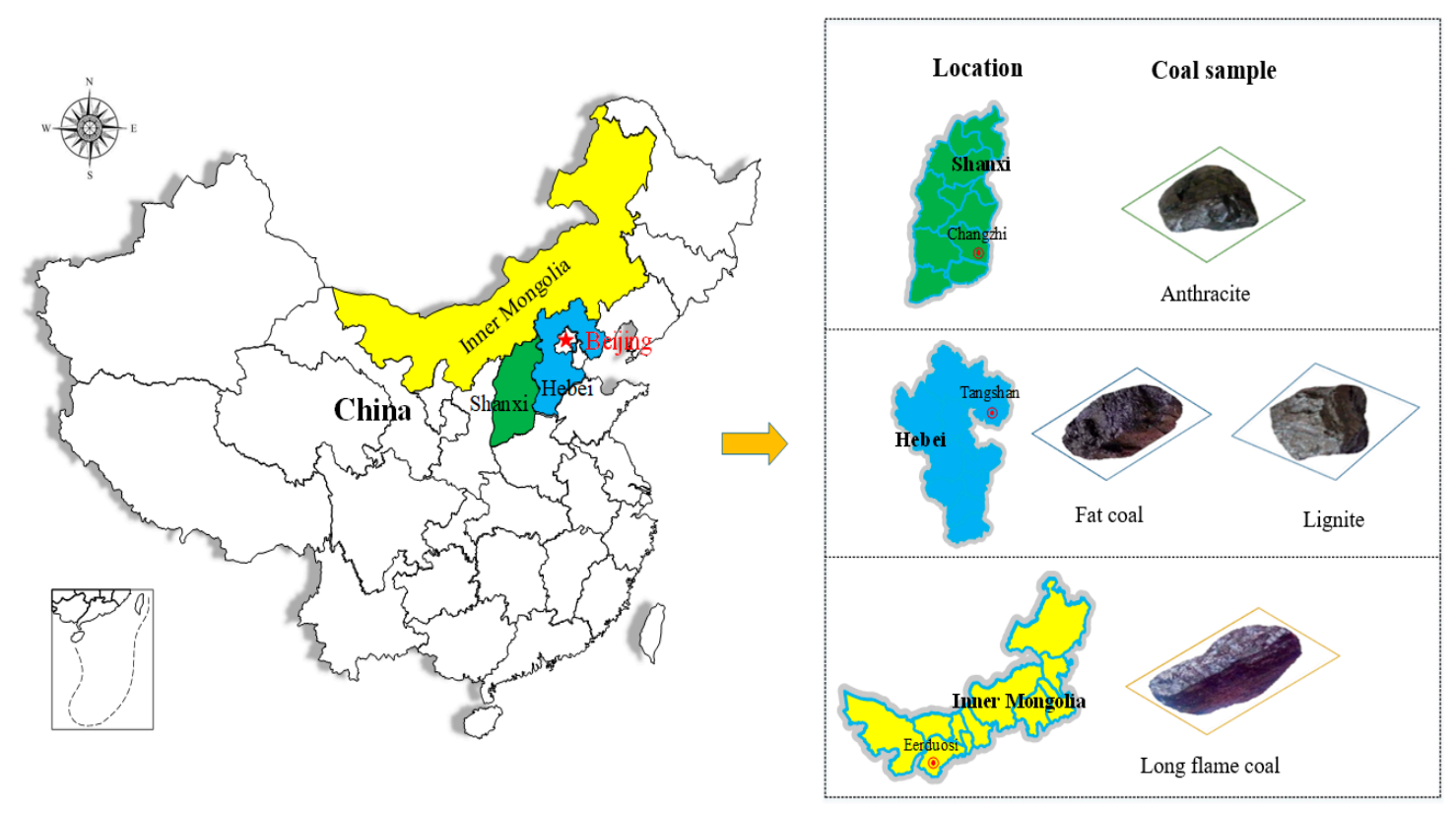

Figure 1. Location distribution of coal samples.

These coal samples were processed as follows: (1) fresh coal blocks were gathered in situ from each coal mine and sealed and transported back to the laboratory; (2) the surface oxide layer was stripped from the raw coal block; (3) pulverized and sieved into particles with a size of 0.18-0.25 mm and $0.048-0.147 \mathrm{~mm}$; and (4) the coal samples were stored in vacuum-sealed glass bottles. Table 1 lists the proximate analysis results for the different metamorphic grade coals. 
Table 1. Proximate analysis of coal samples.

\begin{tabular}{ccccc}
\hline \multirow{2}{*}{ Coal Samples } & \multicolumn{4}{c}{ Proximate Analysis $\mathbf{( \% )}$} \\
\cline { 2 - 5 } & Misoture $\left(\mathbf{M}_{\mathbf{a d}}\right)$ & Ash $\left(\mathbf{A}_{\mathbf{a d}}\right)$ & Volatiles $\left(\mathbf{V}_{\mathbf{a d}}\right)$ & Fixed Carbon $\left(\mathbf{F}_{\mathbf{C a d}}\right)$ \\
\hline Changcun & 0.845 & 11.795 & 11.190 & 76.170 \\
Fangezhuang & 1.995 & 8.960 & 26.615 & 62.430 \\
Neimenggu & 2.895 & 28.250 & 24.190 & 44.665 \\
Cuijiazhai & 12.145 & 8.990 & 33.550 & 45.315 \\
\hline
\end{tabular}

\subsubsection{Preparation of Coal Samples with Different Low Moisture Content}

According to experimental requirements, we prepared four types of coal samples with low moisture contents of $1.2 \%, 3.4 \%, 5.6 \%$, and $7.8 \%$ for each type of coal with the same particle size using the interlayer sprinkle method; the particle size was $0.18-0.25 \mathrm{~mm}$ for TPO and $0.048-0.147 \mathrm{~mm}$ for DSC. In brief, (1) the treated coal samples with different metamorphic grade were placed in a thermostatic drying chamber for drying; (2) the volume of moisture required to prepare for different low moisture content coal samples was calculated in advance, and at the same time, the coal samples of each metamorphic grade were weighed and placed into the weighing bottles many times in equal quality; (3) the coal samples of equal quality were placed on the bottom of the bottle and a tiny sprinkler was used to uniformly spray moisture on the coal samples according to the pre-designed moisture volume. Then, on the sprayed coal samples, again a tiny sprinkler was used to uniformly spray moisture on the coal samples for the same quality, and the cycle was continued until the pre-designed moisture content was uniformly sprayed on the coal samples; (4) step (3) was repeated until all designed coal samples and moisture were used up; (5) the prepared coal samples were placed into vacuum plastic bags and sealed; (6) they were stored in a shady and cool environment for a period of time before using.

\subsection{Experimental Device and Process}

\subsubsection{Temperature Programmed Oxidation Experiment and Process}

Figure 2 shows the experimental device for temperature programmed oxidation of coal samples. The device consists of a TPO control system, a gas supply system, a standard gas cylinder, a control and filtration system, and a detection and analysis system. The TPO control system is a YI-2000 coal spontaneous combustion features tester; the standard gas is supplied by the standard gas pressure tank; the dry gas is provided by the QPT-300G series nitrogen-hydrogen-air-integrated device; the gas analysis system is a GC7820 gas chromatograph used for acquisition and analysis; and the temperature probe inside the coal sample tank is used to measure the temperature of coal samples.

The experimental steps for the TPO of the coal samples were as follows: (1) the coal spontaneous combustion features tester was preheated to $30^{\circ} \mathrm{C}, 80 \mathrm{mg}$ coal samples were put into the sample tank, and the coal samples were uniformly covered with a $2-3 \mathrm{~mm}$ thick asbestos layer; (2) a filtered air flow was provided to avoid the gas path being blocked, the two ends of the sample tank were closely fastened and the joints between the end of the tank and the inlet/outlet of gas passages were sealed with high-temperature-resistant raw material tape; (3) the sample tank was placed in the coal spontaneous combustion features tester and the TPO experimental system was turned on; (4) a heating rate of $0.3^{\circ} \mathrm{C} / \mathrm{min}$ and a gas flow of $50 \mathrm{~mL} / \mathrm{min}$ was set, the coal samples were heated and data was acquired at every $10{ }^{\circ} \mathrm{C}$ interval from $30^{\circ} \mathrm{C}$ to $160^{\circ} \mathrm{C}$ and at every $20^{\circ} \mathrm{C}$ interval from $160{ }^{\circ} \mathrm{C}$ to $260^{\circ} \mathrm{C}$; (5) the above experimental steps were repeated and the various index gas concentrations of four different metamorphic grade coals at four different low moisture content were obtained; (6) in order to ensure the validity of the experimental data, the same experiment was done at least twice, and if the experimental error proved that the data was valid within $4 \%$, the average of the two results was taken as the final result. 


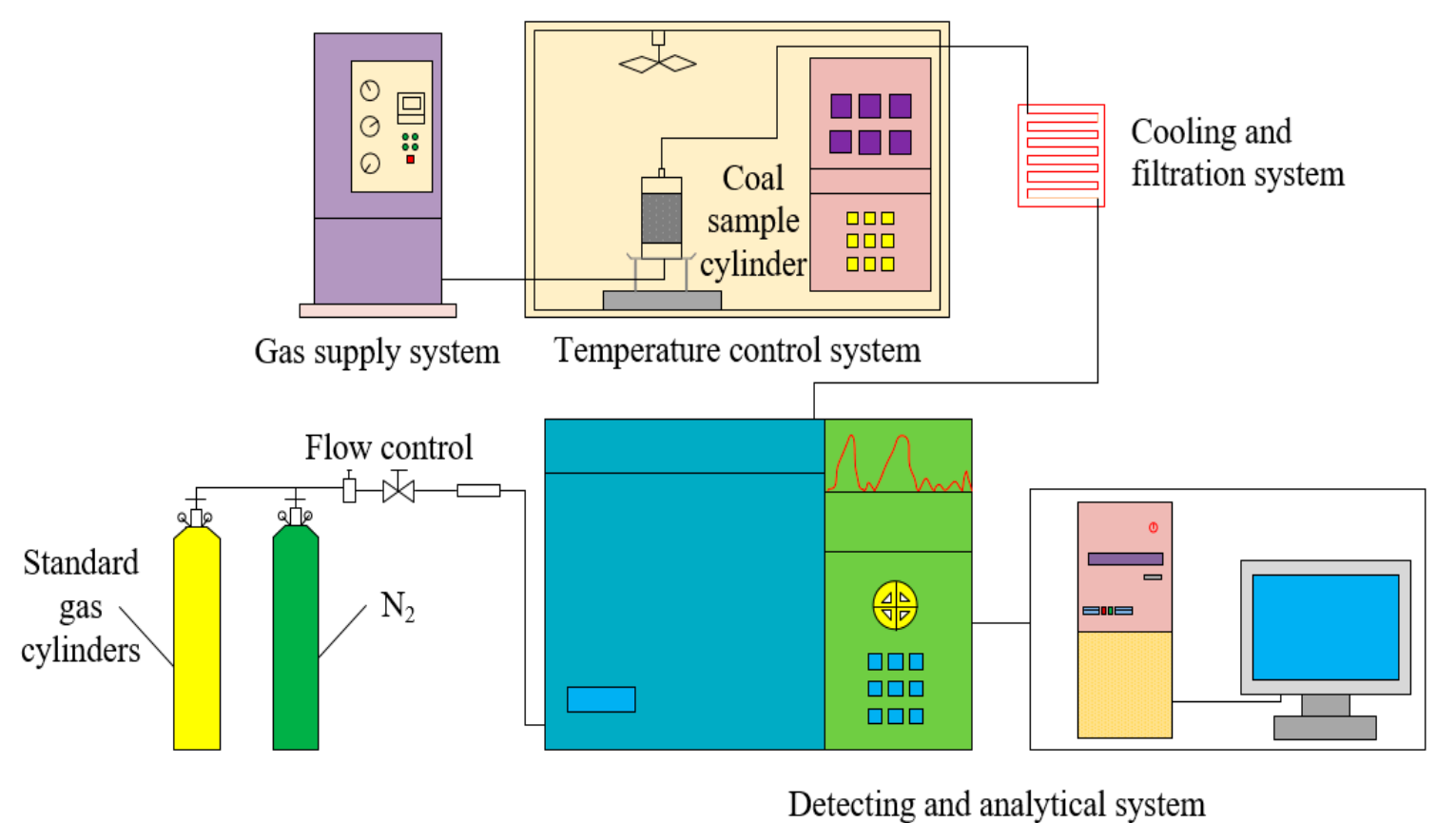

Figure 2. Schematic diagram of apparatus applied for temperature programmed oxidation of coals.

\subsubsection{Differential Scanning Calorimetric Equipment and Process}

Figure 3 shows the experimental principle. Differential scanning calorimetric (DSC) experiments were performed using a DSC200F3 Maia ${ }^{\circledR}$ (NETZSCH Group, Selb, Germany) differential scanning calorimeter manufactured for NETZSCH. The device mainly consists of the "DSC200F3" basic module, cooler, and a computer control system.

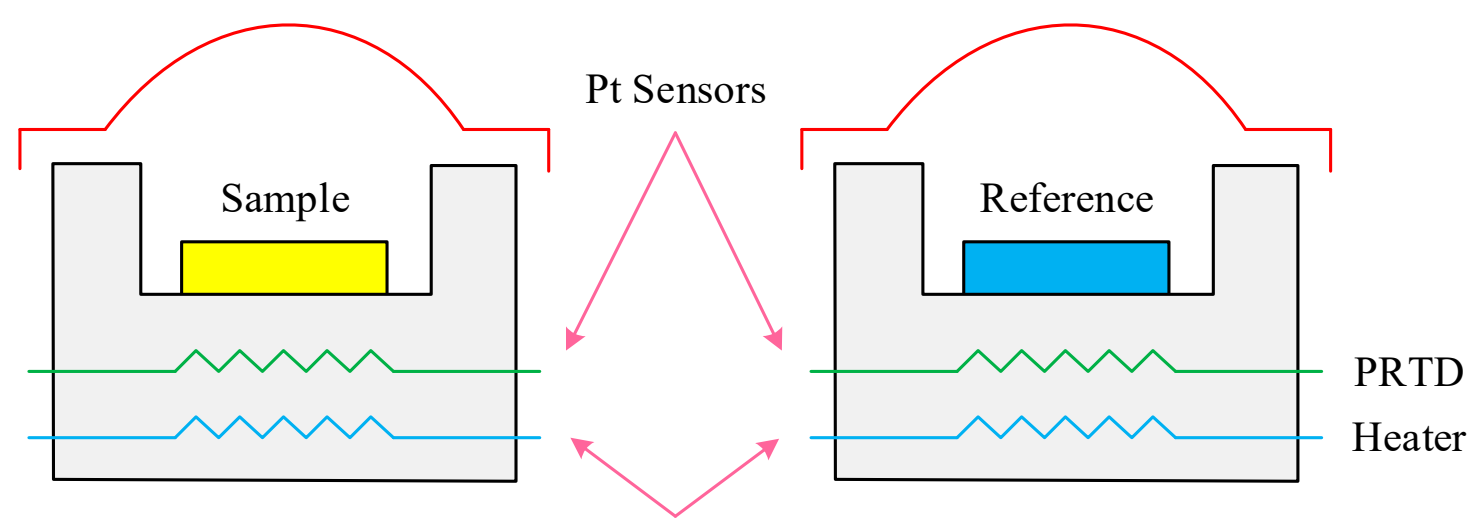

Individual Heaters

Figure 3. The schematic diagram of differential scanning calorimeter.

The experimental steps for DSC of the coal samples were as follows: (1) $10 \mathrm{mg}$ coal samples were put into the furnace chamber together with an reference empty crucible under the condition of satisfying the instrumental sensitivity; (2) the computer control system was turned on to set the experimental parameters for the starting temperature of $25^{\circ} \mathrm{C}$, the ending temperature of $400{ }^{\circ} \mathrm{C}$, the temperature accuracy of $\pm 0.01{ }^{\circ} \mathrm{C}$, heating rate of $5^{\circ} \mathrm{C} / \mathrm{min}$, purge oxygen flow rate of $20 \mathrm{~mL} / \mathrm{min}$, and purge nitrogen flow rate of $80 \mathrm{~mL} / \mathrm{min}$; (3) the coal samples were tested at a protection nitrogen flow rate of $70 \mathrm{~mL} / \mathrm{min}$; (4) the heat flow difference curves of four different metamorphic grade coals at four different low moisture content were drawn; (5) in order to ensure the validity of the experimental data, the same experiment was done at least twice, and if the experimental error proved that the data was valid within $4 \%$, the average of the two results was taken as the final result. 


\section{Results and Discussion}

\subsection{Analysis of Temperature Programmed Oxidation Experimental Results}

To study the effect of four different low moisture contents on the spontaneous combustion characteristics of coals with different metamorphic grades, we conducted the temperature programmed oxidation experiment [30].

\subsection{1. $\mathrm{O}_{2}$ Consumption Concentration}

Figure 4 shows the change of oxygen consumption of four different metamorphic grade coals at four different low moisture contents during the temperature programmed oxidation process. It is clear from Figure 4 that the entire temperature programmed oxidation process of these coal samples has a typical staging characteristic and can be divided into three stages: the slow oxidation stage, the rapid oxidation stage, and the violent oxidation stage.
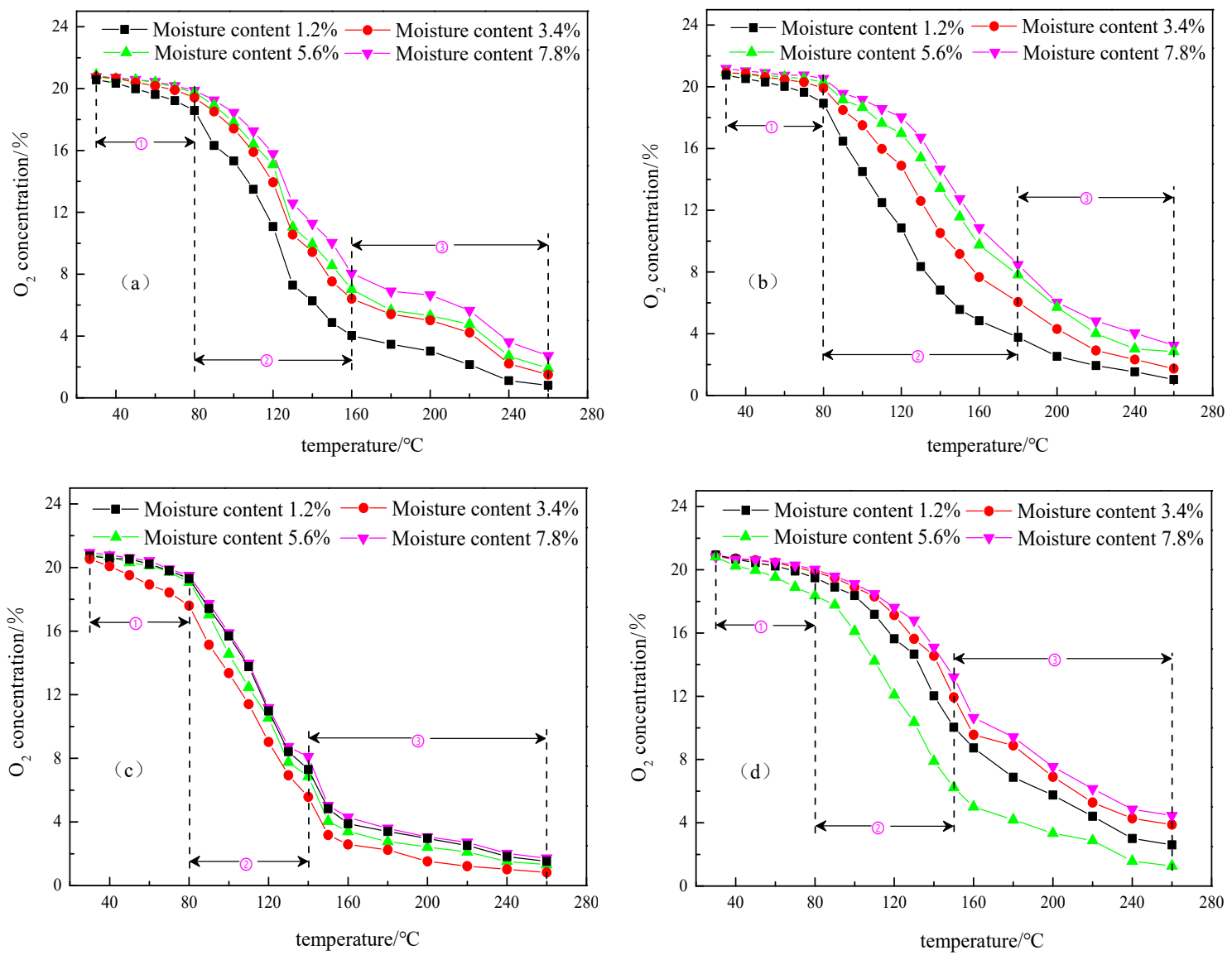

Figure 4. The curves of $\mathrm{O}_{2}$ concentration consumption for anthracite (a), fat coal (b), long flame coal (c), lignite (d) at four different low moisture contents. (1) indicates the slow oxidation stage, (2) indicates the rapid oxidation stage, and (3) indicates the violent oxidation stage.

In the slow oxidation stage, the temperature varying ranges of anthracite, fat coal, long flame coal, and lignite is $30-80{ }^{\circ} \mathrm{C}$. In this range, the overall oxygen consumption of the four different metamorphic grade coals at four different low moisture contents decreases with the rising of temperature. The comparison of oxygen consumption concentration of the four different metamorphic grade coals at four low moisture contents below $80{ }^{\circ} \mathrm{C}$ finds that their overall oxygen consumption displays a slowly dropping tendency. When the coal at low moisture content begins to oxidize, its chemical reaction rate is slow and the rate of oxygen consumption is low. Since the coal is still in the early stage of oxidation reaction, although the rise of its internal moisture promotes the formation of coal-moisture-oxygen 
complex and increases the rate of oxygen consumption, the excessive external moisture staying between the coal molecules hinders oxygen flows; therefore, the change in oxygen consumption is not obvious. In the slow oxidation stage, when the moisture content of the coal samples for anthracite and fat coal are $1.2 \%$, their oxygen consumption is always the maximum. In addition, the oxygen consumption of coal samples at other low moisture contents gradually decrease with the increase of moisture content. The higher the moisture content, the longer the moisture evaporation time, the more the heat is absorbed by evaporation, and the longer the oxygen adsorption is blocked, indicating that increase in moisture content inhibits their internal oxidation degree. For long flame coal and lignite, at a moisture content of $3.4 \%$ and $5.6 \%$, respectively, the oxygen consumption is the highest in the slow oxidation stage.

From Figure 4, it is clear that the rapid oxidation stages of anthracite, fat coal, long flame coal, and lignite are $80-160{ }^{\circ} \mathrm{C}, 80-180{ }^{\circ} \mathrm{C}, 80-140{ }^{\circ} \mathrm{C}$, and $80-150{ }^{\circ} \mathrm{C}$, thus showing significant differences. This is based on the behavior of the oxidation consumption curves for the end points (temperature) in the rapid oxidation stage. In this stage, oxygen consumption of four different metamorphic grade coals at four low moisture contents significantly increases. It shows that the degree of coal oxygen reaction is larger, the moisture in the coal samples gradually evaporates completely, and the flow of oxygen is increased. Therefore, the formation of a moisture-oxygen complex is accelerated. The rapid oxidation of coal samples gradually turn physical and chemical adsorption to chemical reaction, leading to gradual increase in active groups on the surface of coal samples. The oxygen consumption of anthracite and fat coal gradually decreases with the increasing of moisture content. When the moisture content of coal samples for anthracite and fat coal are $1.2 \%$, their oxygen consumption is still the maximum. This can be explained by the fact that a small amount of moisture can immerse the coal with a high or medium metamorphic grade, and it can increase their internal pores. Therefore, it is beneficial to the physical adsorption of oxygen by coal. At the same time, moisture as a catalyst participates in the formation of moisture-oxygen complexes, which further promotes the chemical reaction of coal. However, with the increase of moisture content, the pores in coal with high metamorphism [31] are gradually occupied by moisture, resulting in a drop in the ability of coal to adsorb oxygen. In addition, the evaporation of higher moisture content requires more heat, which is not conducive to the oxidation reaction of coal. For long flame coal and lignite, the oxygen consumption is the highest at moisture contents of $3.4 \%$ and $5.6 \%$, respectively. For lignite, the oxygen adsorption increases with moisture content increases, except moisture content at $5.6 \%$. For coals with low metamorphism, the middle-large pores [32] in the internal structure of the coal body are relatively developed, and the ability to prevent coal from adsorbing oxygen is weak in the low moisture content stage. Therefore, there will be a suitable low moisture content to maximize the oxygen consumption concentration of the coal samples.

Stage 3 is the violent oxidation stage. From Figure 4, obviously, the violent oxidation stages of anthracite, fat coal, long flame coal, and lignite are $160-260{ }^{\circ} \mathrm{C}, 180-260^{\circ} \mathrm{C}, 140-260^{\circ} \mathrm{C}$, and $150-260^{\circ} \mathrm{C}$, respectively. In this stage, as the moisture for the four different metamorphic grade coals at four low moisture contents basically fully evaporates and its inhibition gradually disappears, the porosity of the coal samples increases, and the contact surface area of the coal-oxygen composite reaction increases, resulting in a more dramatic coal-oxygen reaction in this stage. Since the full evaporation of moisture inside coal will not affect the oxygen absorption of the coal, the effect of low moisture content on the oxygen consumption are the same as those at Stage 2.

\subsubsection{Analysis of $\mathrm{CO}$ and $\mathrm{CO}_{2}$ Production}

Figures 5 and 6 show the index gases $\mathrm{CO}$ and $\mathrm{CO}_{2}$ produced in the four different metamorphic grade coals at four different low moisture contents in the temperature programmed oxidation process. 

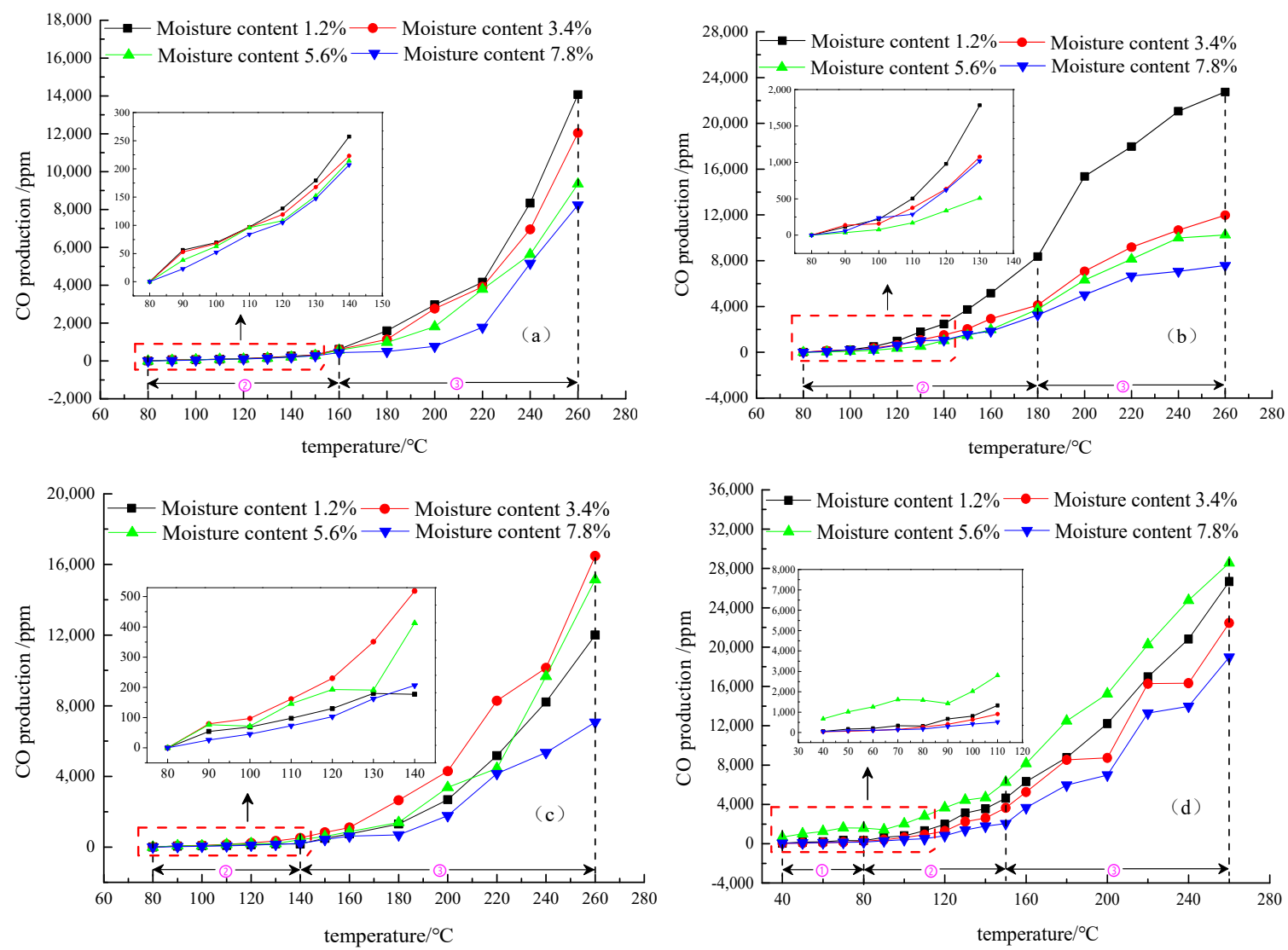

Figure 5. The curves of CO production for anthracite (a), fat coal (b), long flame coal (c), and lignite (d) at four different low moisture content. (1) indicates the slow oxidation stage, (2) indicates the rapid oxidation stage, and (3) indicates the violent oxidation stage.

Figures 5 and 6 clearly show that the production of $\mathrm{CO}$ and $\mathrm{CO}_{2}$ from the four different metamorphic grade coals at four different low moisture contents have the same staging characteristics as their oxygen consumption in the same temperature ranges. However, anthracite, fat coal, and long flame coal did not produce $\mathrm{CO}$ in the slow oxidation stage until the temperature rises to $80^{\circ} \mathrm{C}$. It is proved that $\mathrm{CO}$ is not present in the original coal samples of anthracite, fat coal, and long flame coal. The $\mathrm{CO}$ gas detected during the experiment is produced by coal-oxygen composite reaction, while lignite produces $\mathrm{CO}$ when the temperature rises to $40{ }^{\circ} \mathrm{C}$. The $\mathrm{CO}$ and $\mathrm{CO}_{2}$ production of four different metamorphic grade coals with four different low moisture contents always increases with the rise of temperature. In the slow oxidation stage, $\mathrm{CO}_{2}$ production increases slowly, while in the rapid oxidation stage, $\mathrm{CO}$ and $\mathrm{CO}_{2}$ production increases at a rapid speed, and in the violent oxidation stage, $\mathrm{CO}$ and $\mathrm{CO}_{2}$ production further increases without showing a trend of slowing down. In the overall temperature programmed oxidation process, $\mathrm{CO}$ and $\mathrm{CO}_{2}$ production of anthracite and fat coal gradually decreases with the increase of their low moisture content and are the highest at a moisture content of $1.2 \%$. These results indicate that the two types of coal at a moisture content of $1.2 \%$ undergo a more violent oxidation reaction and show stronger self-ignition risks than other low moisture content coal samples. With moisture content increasing, $\mathrm{CO}$ and $\mathrm{CO}_{2}$ production from long flame coal and lignite at low moisture content does not show a single increase or decrease trend. At the inflection moisture content of $3.4 \%$ and $5.6 \%$, respectively, long flame coal and lignite have the greatest spontaneous combustion risks compared with other low moisture content coal samples. 

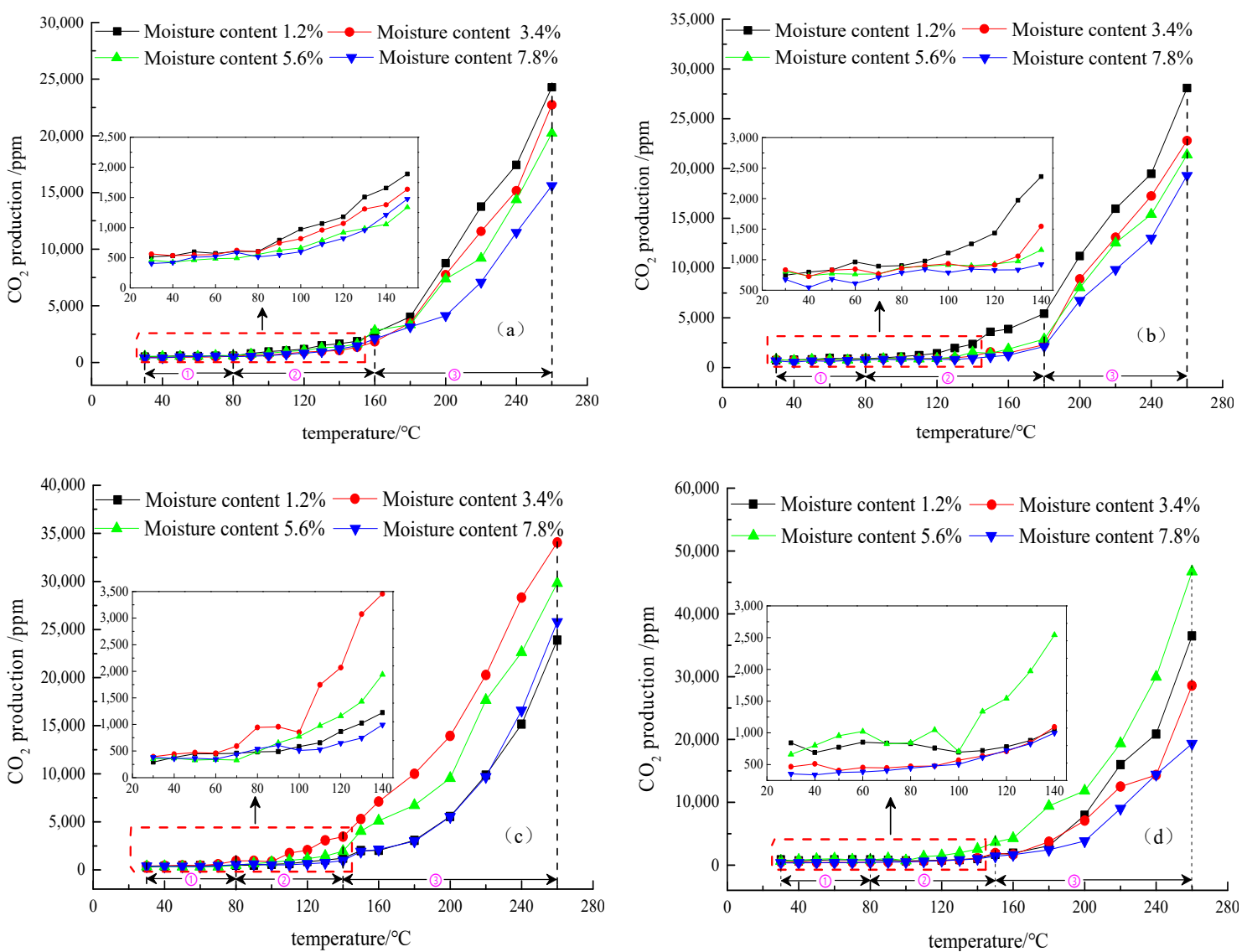

Figure 6. The curves of $\mathrm{CO}_{2}$ production for anthracite (a), fat coal (b), long flame coal (c) and lignite (d) at four different low moisture content. (1) indicates the slow oxidation stage, (2) indicates the rapid oxidation stage, and (3) indicates the violent oxidation stage.

\subsubsection{Maximum Exothermic Strength}

The chemical bond energy method can be used to estimate the maximum exothermic strength, $q_{\max }(T)[33]:$

$$
q_{\max }(T)=\frac{V_{\mathrm{CO}}^{0}(T)}{V_{\mathrm{CO}}^{0}(T)+V_{\mathrm{CO}_{2}}^{0}(T)} \cdot V_{\mathrm{O}_{2}}^{0}(T) \cdot q_{c o}+\frac{V_{\mathrm{CO}_{2}}^{0}(T)}{V_{\mathrm{CO}}^{0}(T)+V_{\mathrm{CO}_{2}}^{0}(T)} \cdot V_{\mathrm{O}_{2}}^{0}(T) \cdot q_{c c_{2}}
$$

where $V_{c o}^{\mathrm{o}}(T)$ and $V_{\mathrm{co}_{2}}^{\mathrm{o}}(T)$ are the $\mathrm{CO}$ and $\mathrm{CO}_{2}$ production rates at temperature $T$ and oxygen concentration $C_{0}, \mathrm{~mol} \cdot \mathrm{cm}^{-3} \cdot \mathrm{s}^{-1} ; V_{O_{2}}^{\mathrm{o}}(T)$ is the oxygen consumption rate of the coal at the temperature $\mathrm{T}$ and oxygen concentration $\mathrm{C}_{0}, \mathrm{~mol} \cdot \mathrm{cm}^{-3} \cdot \mathrm{s}^{-1} ; q_{c o}$ is the average heat released to produce one mol of $\mathrm{CO}$, $q_{c o}=297.0 \mathrm{KJ} \cdot \mathrm{mol}^{-1} ; q_{c o_{2}}$ is the average heat released to produce one $\mathrm{mol}$ of $\mathrm{CO}_{2}, q_{\mathrm{co}_{2}}=446.7 \mathrm{KJ} \cdot \mathrm{mol}^{-1}$; and $V_{o_{2}}^{\mathrm{o}}(T), V_{c o}^{\mathrm{o}}(T)$, and $V_{\mathrm{co}_{2}}^{\mathrm{o}}(T)$ satisfy Equations (2)-(4).

$$
V_{o_{2}}^{0}(T)=\frac{Q \cdot C_{0}}{S \cdot L} \cdot \ln \frac{C_{0}}{C}
$$

where $Q$ is the input air flow rate, $\mathrm{cm}^{3} \cdot \mathrm{s}^{-1} ; S$ is the cross-sectional area of the experimental furnace, $\mathrm{cm}^{2} ; C_{0}$ is the oxygen concentration at the inlet, $21 \% ; C$ is the oxygen concentration at the outlet, $\%$; $L$ is the length of the test coal sample, $\mathrm{cm}$; and $C$ is the oxygen concentration, $\%$. 


$$
\begin{gathered}
V_{\mathrm{CO}}^{0}(T)=\frac{V_{\mathrm{O}_{2}}^{0}(T) \cdot C_{c o}}{C_{0} \cdot\left(1-e^{-\frac{V_{\mathrm{O}_{2}}^{0}(T) \cdot V_{m}}{Q \cdot C_{0}}}\right)} \\
V_{\mathrm{CO}_{2}}^{0}(T)=\frac{V_{\mathrm{O}_{2}}^{0}(T) \cdot C_{c O_{2}}}{C_{0} \cdot\left(1-e^{-\frac{V_{\mathrm{O}_{2}}^{0}(T) \cdot V_{m}}{Q \cdot C_{0}}}\right)}
\end{gathered}
$$

where $C_{c o}$ and $C_{\mathrm{Co}_{2}}$ are $\mathrm{CO}$ and $\mathrm{CO}_{2}$ concentrations at the outlet, ppm; and $V_{\mathrm{m}}$ is the volume of the test coal sample, $\mathrm{cm}^{3}$.

Figure 7 shows the maximum exothermic strength calculated by inputting the data of four different metamorphic grade coals at four low moisture contents measured in the temperature programmed oxidation process into Equations (1)-(4). It is clear from Figure 7 that the maximum exothermic strength of the four different metamorphic grade coals at four low moisture contents have the same staging temperature ranges as $\mathrm{O}_{2}, \mathrm{CO}$, and $\mathrm{CO}_{2}$ productions. In the slow oxidation stage, the maximum exothermic strength of the coal samples differs slightly and is barely affected by low moisture content. This phenomenon is caused by the fact that at a low temperature, both the physico-chemical adsorption of oxygen by coal and the wetting heat of moisture release heat, but this area of heat is relatively smaller. At the same time, at this stage, the moisture of coal continues to undergo slow evaporation and heat absorption. The vapor pressure generated during the evaporation process will prevent the oxygen from contacting the coal body to a certain extent [34], thereby reducing the heat release. Subject to the joint effect of the above factors, although coal samples will release heat, its heat releasing is generally slower.

In the rapid oxidation stage, the maximum exothermic strength shows significant differences. It is clear from Figure 7 that for anthracite and fat coal, their maximum exothermic strength gradually decreases with moisture content increasing, indicating that low moisture content hinders heat release from the coal samples. A low moisture content of 1.2\% facilitates the exothermic effect of coal. The lower the moisture content of anthracite and fat coal, the greater the exothermic intensity and the stronger the promoting effect for temperature programmed oxidation. Thus, a rise in coal sample temperature enhances the spontaneous combustion risk of coal. The reason is that on the one hand, it is related to the distribution of pores in coals with a high or medium metamorphic grade. On the other hand, it may be that the evaporation of moisture at this stage is large. Thus, the vapor pressure on the surface of the coal is high. As moisture evaporates, pores that are substantially exposed and also the moisture-oxygen complex formed in the early stage gradually exhibit an effect. Thus, under the influence of multiple factors, coal-oxygen composite reaction gradually slows down, leading to a drop in heat release. For long flame coal, its maximum exothermic strength shows a trend of increase before decrease with the increase of low moisture content, and at a moisture content of $3.6 \%$, its overall exothermic strength is the greatest. For lignite, its maximum exothermic strength displays a trend of decrease before increase then decrease again with the increase of low moisture content, and at a moisture content of $5.4 \%$, its overall exothermic strength is the highest. These phenomena show that low moisture content has both hindrance and promotion effects on the heat released from coals with low metamorphic grade, the reason for which is related to the pore structures of coals with a low metamorphic grade. In the violent oxidation stage, with the complete evaporation of moisture in the coal, the inhibition gradually disappears and the porosity of the coal increases, resulting in an increase of the coal-oxygen contact area. Thus, as the reaction becomes violent, the coal temperature further increases and the exothermic strength of the coal accordingly enhances, showing approximately an exponential growth trend. In this stage, the effects of different low moisture content on the maximum exothermic strength of each coal are the same as those in the previous stage. 

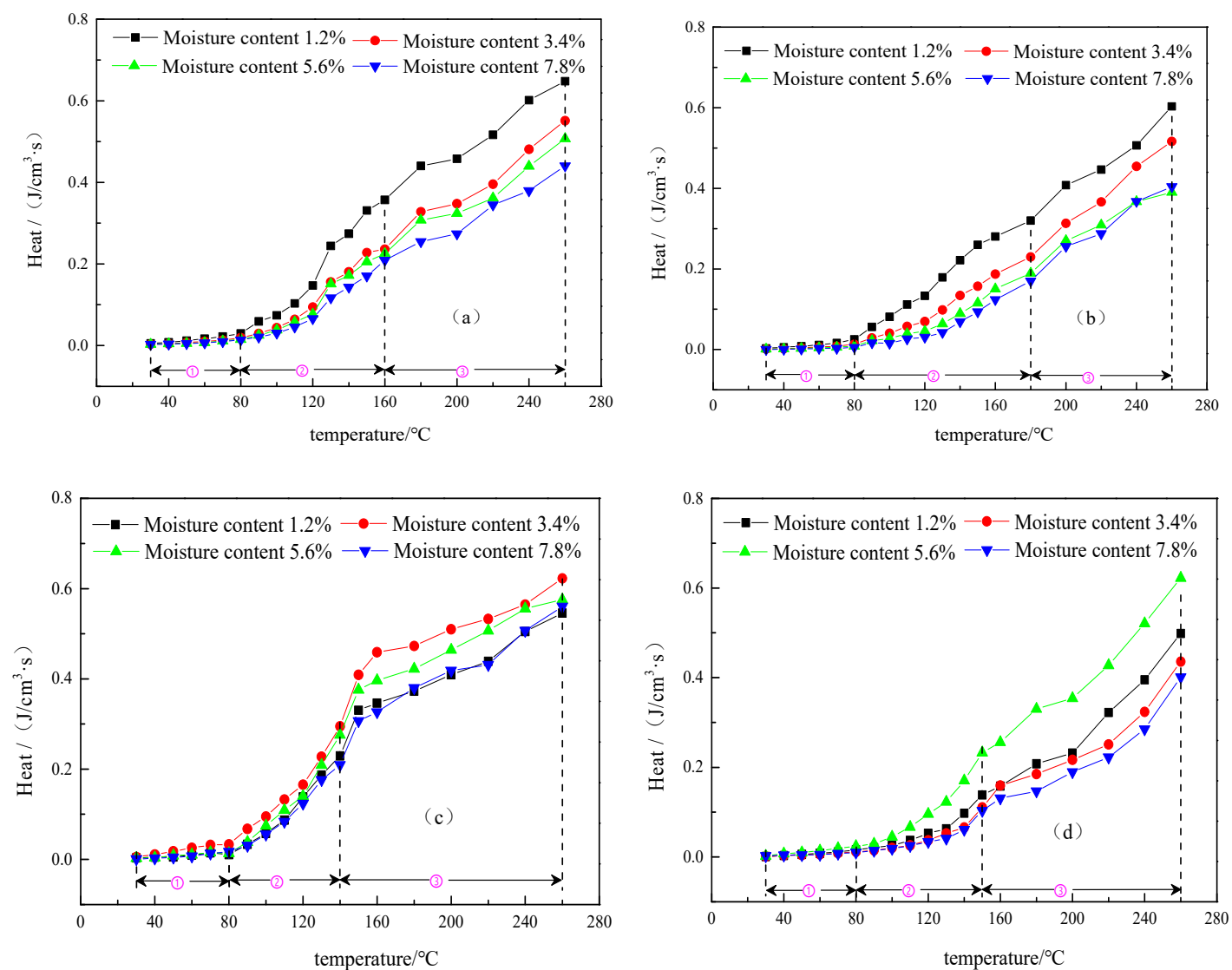

Figure 7. The curves of maximum exothermic strength for anthracite (a), fat coal (b), long flame coal (c) and lignite (d) at four different low moisture contents. (1) indicates the slow oxidation stage, (2) indicates the rapid oxidation stage, and (3) indicates the violent oxidation stage.

\subsection{The Analysis for Scanning Calorimetric Experiment Results}

Having studied the influence of four low moisture contents on the spontaneous combustion characteristics of four different metamorphic grade coals in temperature programmed oxidation process, in order to further study the mechanism of this law for the samples, a differential scanning calorimetry experiment was used for research [35].

\subsubsection{The Analysis of the Zero Point of Heat Flow Difference and Endothermic Peak Temperature}

The DSC curves of the four different metamorphic grade coals at four low moisture contents are shown in Figure 8. The DSC curve reflects the variation tendency of the heat flow difference with temperature during the temperature programmed oxidation process of coals. The curve's abscissa represents the sample temperature and the ordinate represents the heat flow difference changes. 

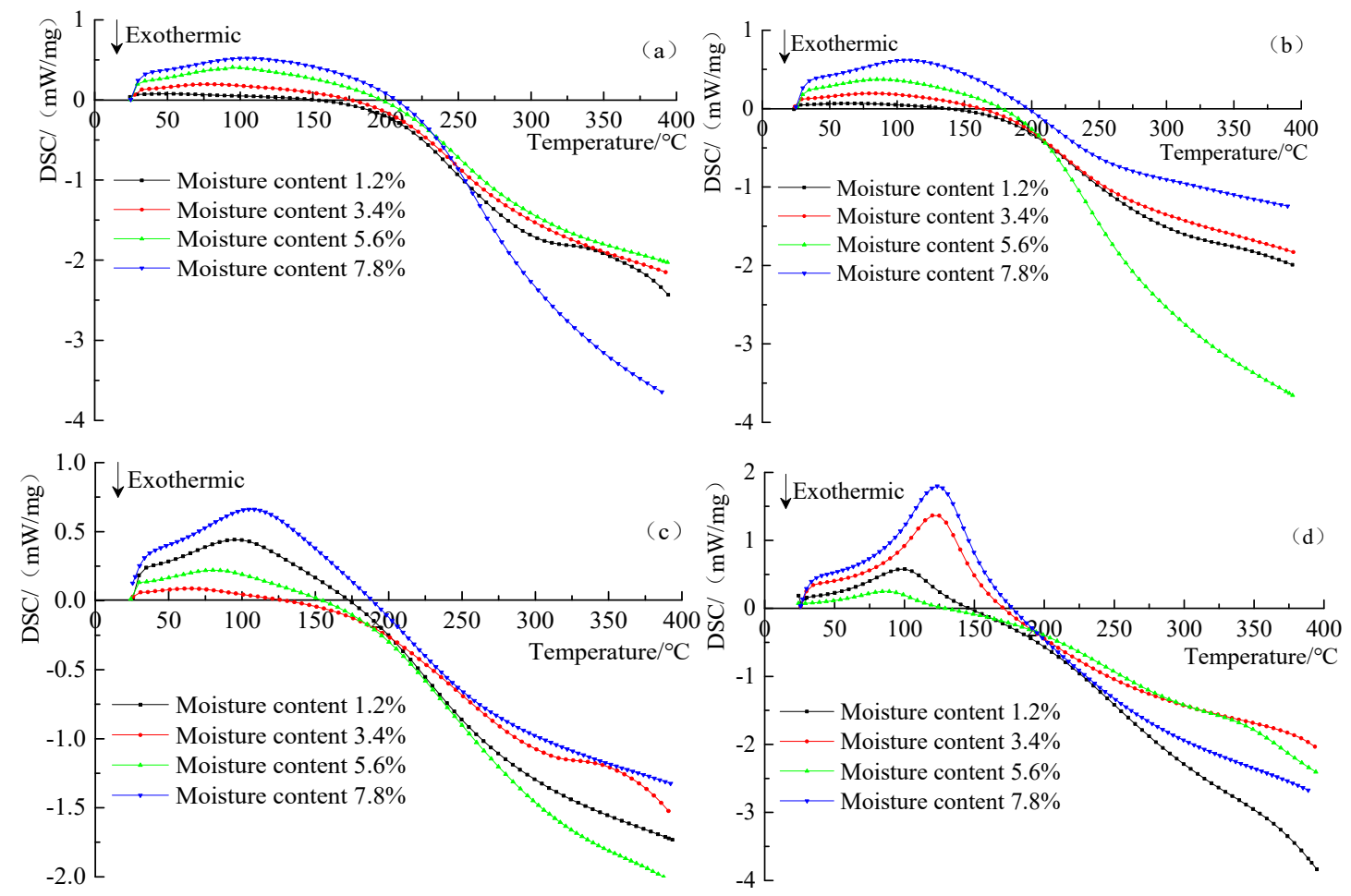

Figure 8. The DSC curves for anthracite (a), fat coal (b), long flame coal (c) and lignite (d) at four different low moisture contents.

It is observed from Figure 8 that the DSC curves of four different metamorphic grade coals at four low moisture contents show a trend of gradually increasing to the peak before gradually decreasing. When the temperature gradually increases, the moisture in the coal gradually evaporates, and the coal absorbs heat. When the experimental temperature further increases, the degree of oxidation reaction of the coal is intensified, and the heat release is gradually increased. It can be clearly observed that the curve is divided into two main stages, namely the endothermic stage and the exothermic stage. The intersection of the curve and the abscissa is the zero point of the heat flow difference [36], that is, the corresponding temperature value when the heat absorption rate is equal to the heat release rate. The zero point of heat flow difference is used as the critical point of the coal between heat absorption and release. Before the zero point, the coal is in an endothermic state, while after the zero point, the coal is in an exothermic state. The zero point of heat flow difference and the endothermic peak temperature are important characteristic parameters for spontaneous combustion of coal. If the zero point of heat flow difference is in the stage of temperature oxidation of coal, its later appearance indicates that a longer time is needed for the coal to reach the endothermic and exothermic transition stages, the heat release occurs in the later stage, the heat storage time is shortened, and the overall heat release of coal is reduced, which eventually causes coal to be less prone to spontaneous combustion. On the contrary, earlier appearance of the heat flow difference zero point means an earlier heat storage time and prolonged overall heat storage time. At this time, the coal is prone to spontaneous combustion. The endothermic peak temperature [37] is the inflection temperature that occurs when the heat flow difference of the coal heat absorption reaches the maximum value in the initial stage of the coal-oxygen compound reaction. Its value is related to the evaporation of water and the exotherm of the chemical reaction. According to Figure 8, the zero point of heat flow difference and the endothermic peak temperature of the four different metamorphic grade coals at four low moisture contents are extracted, as shown in Figure 9. 

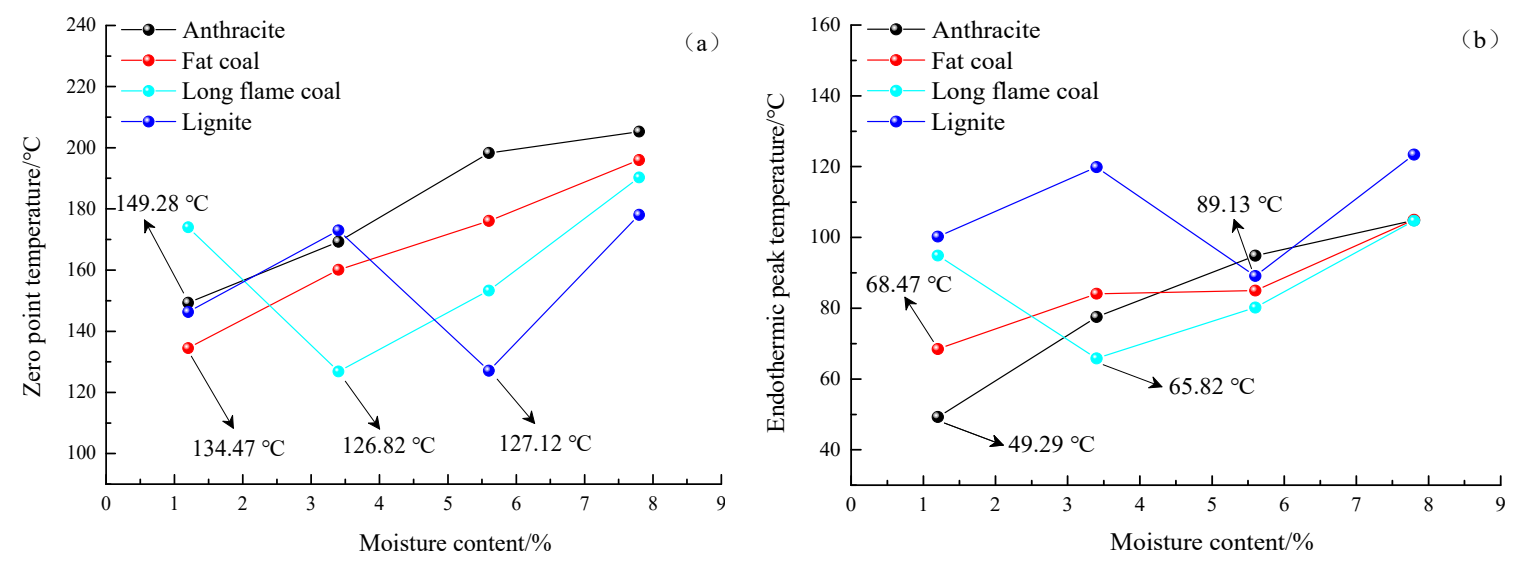

Figure 9. The curves of zero point temperature (a) and endothermic peak temperature (b) for anthracite, fat coal, long flame coal and lignite at four different low moisture contents.

It is known from Figure 9a,b that the zero point of heat flow difference and the endothermic peak temperature of anthracite and fat coal gradually increase with the increase of moisture content. At a low moisture content of $1.2 \%$, the zero point of heat flow difference and the endothermic peak temperature of anthracite and fat coal are the lowest, being $149.28^{\circ} \mathrm{C}$ and $134.47^{\circ} \mathrm{C}$ as well as $49.29^{\circ} \mathrm{C}$ and $68.47^{\circ} \mathrm{C}$, respectively. As the moisture content increases, their zero point of heat flow difference appears later and later. At the same time, in combination with Figure 8, it is known that the peak height and width corresponding to the endothermic peak temperature also increase, resulting in an increase in the endothermic peak area, an increase in total heat absorption, and a decrease in the overall heat release amount of the coal. The results indicate that in the low moisture content stage, the higher the moisture content of the anthracite and fat coal, the more obvious the effect of inhibiting the spontaneous combustion of the coal. Compared with other low moisture content coal samples, spontaneous combustion of anthracite and fat coal at a moisture content of $1.2 \%$ is more likely to occur. The cause is that as coal's metamorphic grade gradually increases, the content of micropores will increase significantly, and the proportion of macropores and mesopores is relatively small. However, the macropores and mesopores in the coal are the main channels for gas diffusing in and out of the coal particles. When the moisture content is low, water molecules occupy the porous surface of coal, which is good for coal to absorb oxygen. When the moisture content gradually increases, the small number of macropores and mesopores are occupied by moisture, which weakens the ability of coal to adsorb oxygen. It reduces the internal surface area for coal and oxygen interaction, which hinders coal-oxygen composite reaction.

The zero point of heat flow difference and endothermic peak temperature of long flame coal show a trend of decreasing to the lowest value before increasing with the moisture content increasing. When the moisture content increases, the zero point of heat flow difference and the endothermic peak temperature both have an inflection point, which is the lowest of $126.82^{\circ} \mathrm{C}$ and $65.82{ }^{\circ} \mathrm{C}$, at a moisture content of $3.4 \%$. The zero point of heat flow difference and endothermic peak temperature of lignite show a trend of increasing to the peak value, followed by a decrease to the lowest value and an increase again with the moisture content increasing. When moisture content increases, the zero point of heat flow difference and the endothermic peak temperature also have an inflection point, which is the lowest of $127.12{ }^{\circ} \mathrm{C}$ and $89.13^{\circ} \mathrm{C}$, at a moisture content of $5.6 \%$. The results show that the effect of low moisture content on the spontaneous combustion characteristics of long flame coal and lignite do not show a single change trend. The optimal moisture content is $3.4 \%$ and $5.6 \%$, respectively, which makes them prone to spontaneous combustion. The mechanism can be summarized as follows. For coals with a low metamorphic grade, the proportions of macropores, mesopores, and transition pores is relatively high, the average pore diameter is large, and the ability to adsorb oxygen is strong. At low moisture content, the pore surface of the coal occupied by water molecules is small. Thus, it is possible for the existence of specific moisture content, at which, oxygen adsorption is stronger than other low 
moisture content coal samples so that the internal surface area for coal and oxygen interaction is greater. Thus, the chemical combustion rate increases. When the moisture content gradually increases, excess moisture will form a water film on the surface of the coal to block oxygen. When a small amount of oxygen is adsorbed by the coal, most of the released heat will be absorbed and consumed by the moisture so that the heat around the coal is difficult to accumulate, thereby delaying the temperature oxidation of the coal.

As shown in Figure 10, anthracite, fat coal, long flame coal, and lignite with low moisture content $(1.2 \%, 3.4 \%, 5.6 \%$, and $7.8 \%)$ showed the strongest tendency to spontaneous combustion danger at moisture contents of $1.2 \%, 1.2 \%, 3.4 \%$, and $5.6 \%$, and a low tendency to spontaneous combustion danger at a moisture content of $7.8 \%$. In other words, the moisture content of coals that are least prone to spontaneous combustion danger is the highest among the four different low moisture contents. This is because water molecules occupy most of the pores on the surface of coals with the possible highest moisture content, forming an aqueous liquid film. This film together with the high vapor pressure in coal act as an oxygen barrier. In addition, most heat released by oxidation reaction of the coal at low temperature will be absorbed by the water evaporation, which reduces the calorific value of the coal as a whole, making it difficult to accumulate heat around the coal, and prolonging the incubation period of coal spontaneous combustion.

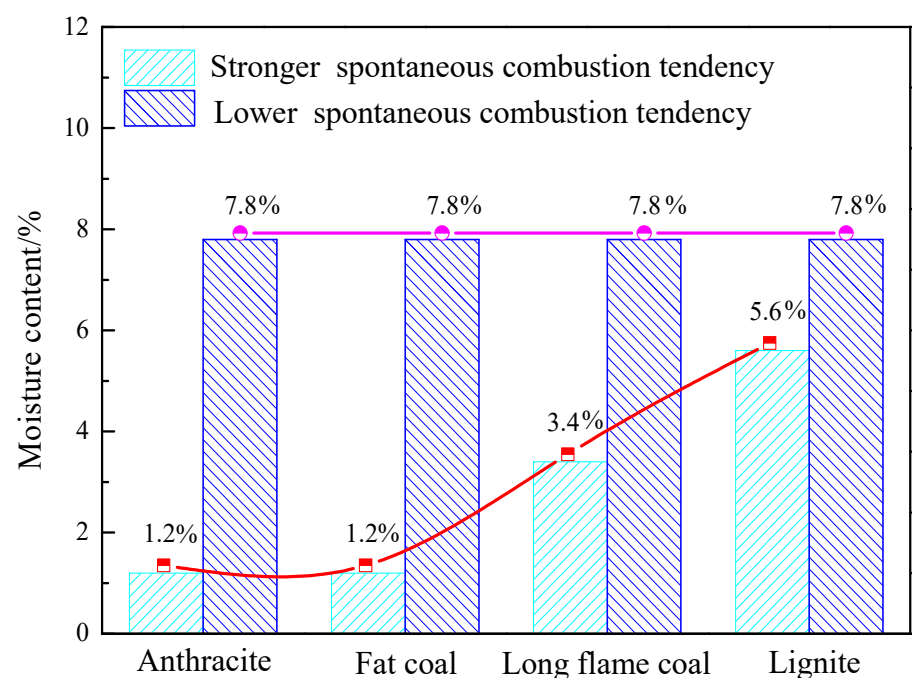

Figure 10. The curves of flammable moisture content and non-flammable moisture content for anthracite, fat coal, long flame coal, and lignite at four different low moisture contents.

\subsubsection{The Analysis of Zero Point of Heat Flow Difference at the Same Low Moisture Content}

Figure 11 compares the zero point of heat flow difference of the four different metamorphic grade coals at the same low moisture content. It can be seen from the figure that at a moisture content of $1.2 \%$, fat coal has the lowest zero point of heat flow difference of $134.47^{\circ} \mathrm{C}$ and long flame coal has the highest zero point of heat flow difference of $173.98^{\circ} \mathrm{C}$. It indicates that at the moisture content of $1.2 \%$, fat coal shows a stronger tendency to spontaneous combustion and long flame coal shows a low spontaneous combustion tendency. At a moisture content of 3.4\%, long flame coal has the lowest zero point of heat flow difference of $126.82{ }^{\circ} \mathrm{C}$, lignite has the highest zero point of heat flow difference of $172.98^{\circ} \mathrm{C}$. It indicates that at a moisture content of $3.4 \%$, long flame coal shows a stronger tendency to spontaneous combustion and lignite shows a low spontaneous combustion tendency. Figure 11 also shows that at a moisture content of $5.6 \%$ and $7.8 \%$, lignite has the lowest zero point of heat flow difference of $127.12{ }^{\circ} \mathrm{C}$ and $178.05^{\circ} \mathrm{C}$ and anthracite has the highest zero point of heat flow difference of $198.29^{\circ} \mathrm{C}$ and $205.29^{\circ} \mathrm{C}$. It indicates that at a moisture content of $5.6 \%$ and $7.8 \%$, lignite is more prone to spontaneous combustion and anthracite is less prone. Overall, the above analyses show that coals with different metamorphic grades have a different spontaneous combustion tendency at the same 
low moisture content. In addition, the same coal at a different low moisture has a different tendency to spontaneous combustion. Moreover, at the same low moisture content, with moisture gradually increasing, lignite is the most prone to spontaneous combustion [38] and anthracite is the least prone to spontaneous combustion.

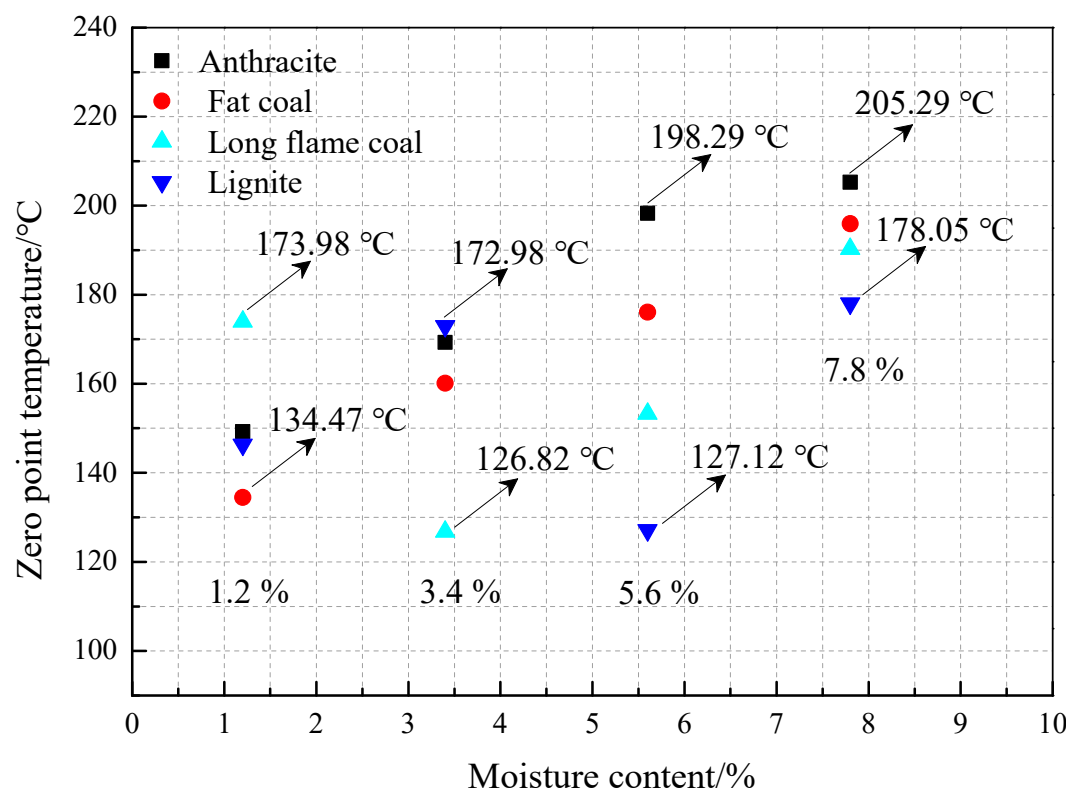

Figure 11. Comparison of the zero point of heat flow difference for anthracite, fat coal, long flame coal and lignite at the same low moisture content.

\section{Conclusions}

The characteristics of spontaneous combustion of four different metamorphic grade coals at four low moisture contents were studied in a temperature programmed oxidation experiment and differential scanning calorimetric experiment. The following conclusions were obtained.

(1) At low moisture content, with moisture content increasing, the zero point of heat flow difference of anthracite and fat coals appears later, the endothermic peak area increases, overall heat release decreases, and risk of spontaneous combustion weakens. When the moisture content is $1.2 \%$, anthracite and fat coal show a stronger tendency of spontaneous combustion. By contrast, long flame coal and lignite are more prone to spontaneous combustion when the moisture content is $3.4 \%$ and $5.6 \%$. When the moisture content is $7.8 \%$, all four types of coals have a low tendency of spontaneous combustion. In order to prevent the spontaneous combustion of coal, the moisture content of coal should be kept above $7.8 \%$.

(2) At the same low moisture content, the coals with different metamorphic grade have different spontaneous combustion tendencies and do not exhibit certain regular characteristics. At low moisture content, with moisture content increasing, for the four types of coals, lignite is most prone to spontaneous combustion and anthracite is least prone to spontaneous combustion.

(3) The temperature programmed oxidation process of four different metamorphic grade coals at four low moisture contents experienced three similar stages: slow oxidation stage, rapid oxidation stage, and violent oxidation stage. The temperature ranges of four types of coals are different in each stage. In the three different oxidation stages, the oxygen consumption of anthracite and fat coal decreased with the increase of low moisture content, and coal samples at a moisture content of $1.2 \%$ consume the most oxygen. By contrast, long flame coal and lignite at a moisture content of $3.4 \%$ and $5.6 \%$ consume the most oxygen in the three stages.

(4) During the overall temperature oxidation process, the production of $\mathrm{CO}$ and $\mathrm{CO}_{2}$ and the maximum exothermic strength of anthracite and fat coal at low moisture content gradually decrease with moisture increasing. When the moisture content of anthracite and fat coal are $1.2 \%$, the amount 
of $\mathrm{CO}$ and $\mathrm{CO}_{2}$ production and the exothermic strength are higher than those at other low moisture contents. This shows a stronger risk of spontaneous combustion. Long flame coal and lignite at a moisture content of $3.4 \%$ and $5.6 \%$, produce more $\mathrm{CO}$ and $\mathrm{CO}_{2}$ and possess higher exothermic strength than other low moisture content coal samples and are more prone to spontaneous combustion.

(5) Through the research results of the spontaneous combustion tendency of coals with different metamorphic grade at low moisture contents based on TPO-DSC, it can be seen that when the coal is affected by external environmental factors to reduce the moisture content, once a fire breaks out, the low moisture content is likely to exacerbate the combustion of coals with different metamorphic grades. In order to prevent the spontaneous combustion tendency of coals with different metamorphic grades at a low moisture content, from the perspective of fire prevention, coal with a low moisture content in various environments including open coal storage sites, mining-affected coalbeds, and goafs should be strictly guarded. Keeping the moisture content of anthracite, fat coal, long flame coal and lignite near the level of $1.2 \%, 1.2 \%, 3.4 \%, 5.6 \%$ should be avoided. By moisturizing, the moisture content of coal is maintained above $7.8 \%$, and the spontaneous combustion hazard is reduced. The research results have a certain role in promoting research on the mechanism of the influence of moisture on coal spontaneous combustion. It provides references for the prevention and control of coal spontaneous combustion in the long-term low moisture content environment.

Author Contributions: G.W. and J.F. conducted the main work and wrote the paper; J.Z. took part in laboratory experiments and finished the related data analysis. They all provided insightful suggestions and revised the paper.

Funding: This research was funded by the National Natural Science Foundation of China (Project No. 51674158), the Taishan Scholar Talent Team Support Plan for Advantaged \& Unique Discipline Areas, the Source Innovation Program (Applied Research Special-Youth Special) of Qingdao (Project No. 17-1-1-38-jch), the Major Program of Shandong Province Natural Science Foundation (Project No. ZR2018ZA0602), and the National Key Research and Development Program of China (Project No. 2017YFC0805201).

Conflicts of Interest: The authors declare no conflicts of interest. The founding sponsors had no role in the design of the study; in the collection, analyses, or interpretation of data; in the writing of the manuscript, and in the decision to publish the results.

\section{References}

1. Yang, Y.; Li, Z.; Si, L.; Gu, F.; Zhou, Y.; Qi, Q.; Sun, X. Study governing the impact of long-term water immersion on coal spontaneous ignition. Arab. J. Sci. Eng. 2016, 42,1-11. [CrossRef]

2. Choi, H.; Thiruppathiraja, C.; Kim, S.; Rhim, Y.; Lim, J.; Lee, S. Moisture readsorption and low temperature oxidation characteristics of upgraded low rank coal. Fuel Process. Technol. 2011, 92, 2005-2010. [CrossRef]

3. Wang, X.; Luo, Y.; Vieira, B. Experimental technique and modeling for evaluating heat of rewetting effect on coals propensity of spontaneous combustion based on adiabatic oxidation method. Int. J. Coal Geol. 2018, 187, 1-10. [CrossRef]

4. Wang, G.; Wang, Y.; Sun, L.; Song, X.; Liu, Q.; Xu, H.; Du, W. Study on the Low-Temperature Oxidation Law in the Co-Mining Face of Coal and Oil Shale in a Goaf-A Case Study in the Liangjia Coal Mine, China. Energies 2018, 11, 174. [CrossRef]

5. Zhong, X.; Kan, L.; Xin, H.; Qin, B.; Dou, G. Thermal effects and active group differentiation of low-rank coal during low-temperature oxidation under vacuum drying after water immersion. Fuel 2019, 236, 1204-1212. [CrossRef]

6. Tang, Y.; Xue, S. Influence of long-term water immersion on spontaneous combustion characteristics of Bulianta bituminous coal. Int. J. Oil Gas Coal Technol. 2017, 14, 398-411. [CrossRef]

7. Miura, K. Adsorption of water vapor from ambient atmosphere onto coal fines leading to spontaneous heating of coal stockpile. Energy Fuels 2015, 30, 219-229. [CrossRef]

8. MT/T 850-2000 (National Standard of China). China Coal Water Classification Industry Standards. Available online: http://www.doc88.com/p-1357829781036.html (accessed on 18 January 2000).

9. Liu, X.; Hirajima, T.; Nonaka, M.; Sasaki, K. Experimental study on freeze drying of Loy Yang lignite and inhibiting water re-adsorption of dried lignite. Colloids Surf. A Physicochem. Eng. Asp. 2017, 520, 146-153. [CrossRef] 
10. Wang, H.; Dlugogorski, B.Z.; Kennedy, E.M. Coal oxidation at low temperatures: Oxygen consumption, oxidation products, reaction mechanism and kinetic modelling. Prog. Energy Combust. Sci. 2003, 29, 487-513. [CrossRef]

11. Kim, J.; Lee, Y.; Ryu, C.; Park, H.Y.; Lim, H. Low-temperature reactivity of coals for evaluation of spontaneous combustion propensity. Korean J. Chem. Eng. 2015, 32, 1297-1304. [CrossRef]

12. Zhang, K.; You, C. Effect of upgraded lignite product water content on the propensity for spontaneous ignition. Energy Fuels 2012, 27, 20-26. [CrossRef]

13. Hu, Z.; Xia, Q. An integrated methodology for monitoring spontaneous combustion of coal waste dumps based on surface temperature detection. Appl. Therm. Eng. 2017, 122, 27-38. [CrossRef]

14. Xiao, Y.; Lü, H.F.; Huang, A.C.; Deng, J.; Shu, C.M. A new numerical method to predict the growth temperature of spontaneous combustion of $1 / 3$ coking coal. Appl. Therm. Eng. 2018, 131, 221-229. [CrossRef]

15. Arisoy, A.; Beamish, B. Mutual effects of pyrite and moisture on coal self-heating rates and reaction rate data for pyrite oxidation. Fuel 2015, 139, 107-114. [CrossRef]

16. Arisoy, A.; Beamish, B.; Yoruk, B. Moisture moderation during coal self-heating. Fuel 2017, 210, 352-358. [CrossRef]

17. Xuyao, Q.; Wang, D.; Milke, J.A.; Zhong, X. Crossing point temperature of coal. Min. Sci. Technol. (China) 2011, 21, 255-260. [CrossRef]

18. Yu, J.; Tahmasebi, A.; Han, Y.; Yin, F.; Li, X. A review on water in low rank coals: The existence, interaction with coal structure and effects on coal utilization. Fuel Process. Technol. 2013, 106, 9-20. [CrossRef]

19. Kadioğlu, Y.; Varamaz, M. The effect of moisture content and air-drying on spontaneous combustion characteristics of two Turkish lignitesa. Fuel 2003, 82, 1685-1693. [CrossRef]

20. Beamish, B.B.; Hamilton, G.R. Effect of moisture content on the R70 self-heating rate of Callide coal. Int. J. Coal Geol. 2005, 64, 133-138. [CrossRef]

21. Deng, J.; Liu, W.Y.; Zhai, X.W.; Wen, H. Research on the Effects of Moisture on Oxidation and Spontaneous Combustion Properties of Mengba Coal Mine. Saf. Coal Mines (China) 2011, 42, 15-19.

22. Song, S.; Qin, B.; Xin, H.; Qin, X.; Chen, K. Exploring effect of water immersion on the structure and low-temperature oxidation of coal: A case study of Shendong long flame coal, China. Fuel 2018, 234, 732-737. [CrossRef]

23. Wang, H.; Dlugogorski, B.Z.; Kennedy, E.M. Role of inherent water in low-temperature oxidation of coal. Combust. Sci. Technol. 2003, 175, 253-270. [CrossRef]

24. Zhang, Z.; Yan, K. Molecular dynamics simulation of oxygen diffusion in dry and water-containing brown coal. Mol. Phys. 2011, 109, 2367-2374. [CrossRef]

25. Li, Y.; Zhao, H.; Song, Q.; Wang, X.; Shu, X. Influence of critical moisture content in lignite dried by two methods on its physicochemical properties during oxidation at low temperature. Fuel 2018, 211, 27-37. [CrossRef]

26. Chen, X.D.; Stott, J.B. The effect of moisture content on the oxidation rate of coal during near-equilibrium drying and wetting at 50 C. Fuel 1993, 72, 787-792. [CrossRef]

27. Zhao, H.; Yu, J.; Liu, J.; Tahmasebi, A. Experimental study on the self-heating characteristics of Indonesian lignite during low temperature oxidation. Fuel 2015, 150, 55-63. [CrossRef]

28. Wang, W.; Wang, G.; Liu, H. Heat release regular pattern of different moisture content coal in low temperature. CSIRO Earth Sci. Resour. Eng. 2013, 94, 419-425.

29. Xu, T.; Wang, D.M.; He, Q.L. The study of the critical moisture content at which coal has the most high tendency to spontaneous combustion. Int. J. Coal Prep. Util. 2013, 33, 117-127. [CrossRef]

30. Li, J.; Fu, P.; Zhu, Q.; Mao, Y.; Yang, C. A lab-scale experiment on low-temperature coal oxidation in context of underground coal fires. Appl. Therm. Eng. 2018, 141, 333-338. [CrossRef]

31. Wang, F.; Cheng, Y.; Lu, S.; Jin, K.; Zhao, W. Influence of coalification on the pore characteristics of middle-high rank coal. Energy Fuels 2014, 28, 5729-5736. [CrossRef]

32. Yao, Y.; Liu, D. Comparison of low-field NMR and mercury intrusion porosimetry in characterizing pore size distributions of coals. Fuel 2012, 95, 152-158. [CrossRef]

33. Wang, G.; Liu, Q.; Sun, L.; Song, X.; Du, W.; Yan, D.; Wang, Y. Secondary spontaneous combustion characteristics of coal based on programed temperature experiments. J. Energy Resour. Technol. 2018, 140, 082204. [CrossRef]

34. Küçük, A.; Kadıoğlu, Y.; Gülaboğlu, M.Ş. A study of spontaneous combustion characteristics of a Turkish lignite: Particle size, moisture of coal, humidity of air. Combust. Flame 2003, 133, 255-261. [CrossRef] 
35. Tahmasebi, A.; Yu, J.; Su, H.; Han, Y.; Lucas, J.; Zheng, H.; Wall, T. A differential scanning calorimetric (DSC) study on the characteristics and behavior of water in low-rank coals. Fuel 2014, 135, 243-252. [CrossRef]

36. Zhang, B.; Fu, P.; Liu, Y.; Yue, F.; Chen, J.; Zhou, H.; Zheng, C. Investigation on the ignition, thermal acceleration and characteristic temperatures of coal char combustion. Appl. Therm. Eng. 2017, 113, 1303-1312. [CrossRef]

37. Cui, C.; Jiang, S.; Shao, H.; Zhang, W.; Wang, K.; Wu, Z. Experimental study on thermo-responsive inhibitors inhibiting coal spontaneous combustion. Fuel Process. Technol. 2018, 175, 113-122. [CrossRef]

38. Feng, X.; Zhang, C.; Tan, P.; Zhang, X.; Fang, Q.; Chen, G. Experimental study of the physicochemical structure and moisture readsorption characteristics of Zhaotong lignite after hydrothermal and thermal upgrading. Fuel 2016, 185, 112-121. [CrossRef]

(C) 2019 by the authors. Licensee MDPI, Basel, Switzerland. This article is an open access article distributed under the terms and conditions of the Creative Commons Attribution (CC BY) license (http://creativecommons.org/licenses/by/4.0/). 